\title{
Feasibility and outcome of clean intermittent catheterization for children with sensate urethra
}

\author{
Khalid Fouda Neel, FRCSI
}

See related article on page 406.

\section{Abstract}

Objective: Clean intermittent catheterization $(\mathrm{CIC})$ is an important asset in managing children with noncompliant bladders. We review the feasibility and late outcomes of patients with normal urethral sensation who began $\mathrm{CIC}$.

Materials and methods: We reviewed all patients with posterior urethral valve (PUV) or non-neuropathic bladder sphincter dysfunction (NNBSD) who began on CIC, and had at least 2 years of follow-up. We considered their age, indication, acceptance and compliance with CIC. Additionally, we examined the late outcome of bladder function and the need for any surgical intervention at follow-up.

Results: Between 1999 and 2006, 52 patients with PUV (38 patients) or NNBSD (14 patients) were started on CIC. Of these 52 patients, $48 \%$ were under the age of 4 . A total of 44 patients $(85 \%)$ accepted the recommendation for $\mathrm{CIC}$, and 34 patients $(65 \%)$ were compliant with the protocol after at least 2 years of follow-up. The age of the patients was the only significant factor related to the success of the protocol (4 years old or younger, $p=0.03$ ). After at least 2 years of follow-up, 28 patients (54\%) remained on $\mathrm{CIC}$ and have not required urinary diversion or bladder reconstruction. Conclusion: The current study showed that $\mathrm{CIC}$ is a feasible option for patients with sensate urethra, which necessitates the introduction of treatment as early as possible. Further, those patients who are compliant with the CIC demonstrated a better chance of avoiding subsequent surgical intervention for the management of a noncompliant bladder.

Can Urol Assoc J 2010;4(6):403-5

\section{Résumé}

Objectif : Le cathétérisme intermittent propre (CIP) est un élément important de la prise en charge de l'insuffisance vésicale chez les enfants. Nous passons ici en revue la faisabilité et les résultats tardifs chez des patients affichant des sensations urétrales normales qui ont entrepris un traitement par CIP.

Matériel et méthodologie : Nous avons examiné tous les patients atteints d'une dysfonction de la valve urétrale postérieure (DVUP) ou d'une dysfonction non névrotique du sphincter vésical (DNNSV) ayant entrepris un traitement par CIP, et suivis pendant au moins 2 ans. Nous avons tenu compte de leur âge, de I'indication du traitement, de leur acceptation et leur observance du traitement par CIP. En outre, nous avons examiné les résultats tardifs de la fonction vésicale et le besoin de recourir à tout type $\mathrm{d}^{\prime}$ intervention chirurgicale lors du suivi.

Résultats : Entre 1999 et 2006, 52 patients atteints de DVUP (38 patients) ou de DNNSV (14 patients) ont entrepris un traitement par CIP. De ce nombre, $48 \%$ avaient moins de 4 ans. Au total, 44 patients $(85 \%)$ ont accepté la recommandation de procéder au CIP, et 34 patients (65\%) observaient toujours le traitement après au moins 2 ans de suivi. L'âge des patients représentait le seul facteur significatif lié à la réussite du traitement (4 ans ou moins, $p=0,03)$. Après au moins 2 ans de suivi, 28 patients (54\%) poursuivaient leur traitement par CIP et n'avaient pas besoin d'un détournement urinaire ou d'une reconstruction de la vessie. Conclusion : Notre étude a montré que le CIP est une option raisonnable pour les patients avec urètre sensible, qui nécessite I'instauration d'un traitement le plus rapidement possible. Par ailleurs, les patients qui observent bien le traitement par CIP présentaient de meilleures chances d'éviter une intervention chirurgicale subséquente pour le traitement d'une insuffisance vésicale.

\section{Introduction}

Children with both non-neuropathic at-risk bladder secondary to posterior urethral valve (PUV) and non-neuropathic bladder sphincter dysfunction (NNBSD) are a challenge to manage. The children and their families fail to appreciate the complexity of the problem, as the child looks normal and voids normally. Patients and their families may not understand that poor compliance with the treatment protocol could lead to end-stage renal failure in some patients.

The main goal in managing at an at-risk bladder is to lower the intravesical pressure to a safe limit, usually by combining anticholinergic medications and clean intermittent catheterization (CIC). ${ }^{1}$ If this line of treatment is unfeasible or the bladder is refractory to this conservative management, patients may need either non-continent diversion or bladder reconstruction with a continent bladder stoma to preserve their renal function. ${ }^{2}$ As expected, CIC per sensate urethra is a challenge to master, as the compliance of the child and caregiver is difficult to attain. ${ }^{3-5}$

This report assesses the feasibility of $\mathrm{CIC}$ in patients with sensate urethra. The paper also examines the fate of the bladder in the long follow-up period. 


\section{Materials and methods}

A retrospective review of the files of patients diagnosed with PUV or NNBSD in the local unit between 1999 and 2007 was performed. Patients who needed to start CIC per sensate urethra for their at-risk poorly compliant bladder were included. The following factors were examined: acceptance and compliance with $\mathrm{CIC}$, late outcome fate of the bladder, whether this line of treatment was sufficient to protect the upper tract, and the necessity for further surgical interventions.

Clean intermittent catheterization training was done by the urotherapist in the outpatient clinic. Patients with PUV were kept with overnight drainage if hydronephrosis persisted.

Acceptance was defined as the time when the child and caregiver were ready to start $\mathrm{CIC}$ after their first visit with the urotherapist. Compliance was evaluated as whether the caregiver/child was compliant with the protocol for at least 2 years after starting the program. At that time, the child will either: 1) be compliant with $\mathrm{CIC}, 2$ ) have undergone a urinary diversion, 3) have had bladder reconstruction, or 4) have not had any active treatment but are still being followed-up.

\section{Results}

A total of 38 patients with PUV and 14 patients with NNBSB began $\mathrm{CIC}$ per sensate urethra in the urotherapy laboratory since 1999 (Table 1). Clean intermittent catheterization was initiated because of a noncompliant at-risk bladder with or without urinary incontinence in 49 patients; an additional 3 patients started $\mathrm{CIC}$ due to high postvoid residue.

Of the 52 patients, $44(85 \%)$ demonstrated acceptance of the procedure and attended training (Fig. 1). Among the 44 children who accepted and mastered $\mathrm{CIC}, 77 \%$ (34 patients, representing $65 \%$ of the entire group) were still compliant after at least 2 years of follow-up.

A total of 25 patients (48\%) were 4 years old or younger, and 27 (52\%) were over 4 years old upon initiation of the $\mathrm{CIC}$ protocol. For those 4 years or younger, $80 \%$ were compliant with $\mathrm{CIC}$ after at least 2 years of follow-up, and only $52 \%$ of those over 4 years old were compliant at this time $(p=0.03$ ) (Table 1) (Fig. 2). Children who needed CIC per sensate urethra had a $54 \%(28 / 52)$ chance of stabilizing their upper tract, mastering the protocol, achieving compliance and avoiding surgical intervention.

\section{Discussion}

The management of children with neuropathic or non-neuropathic bladder dysfunction is a challenge that requires a team approach. When the condition is severe enough that a patient must started $\mathrm{CIC}$, resistance from the child and the family is understandable; this is particularly true when the child possesses normal urethral sensation. Of the 52 patients in our unit with sensate urethra who required $\mathrm{CIC}, 34$ (65\%) where able to begin and continue the program. This finding is consistent with values from previously published reports; ${ }^{3-5}$ however, this number is less than the number observed in our experience with patients with myelominigocele (MMC). ${ }^{6}$ This discrepancy can be explained by the lack of urethral sensation in MMC patients.

The key factor for success in such a treatment modality is a dedicated team with sufficient time to explain the need for a $\mathrm{CIC}$ program, how the program will be conducted, and the negative consequences on the bladder and kidneys if $\mathrm{CIC}$ is not performed properly. Another important factor associated with success is a discussion with the families

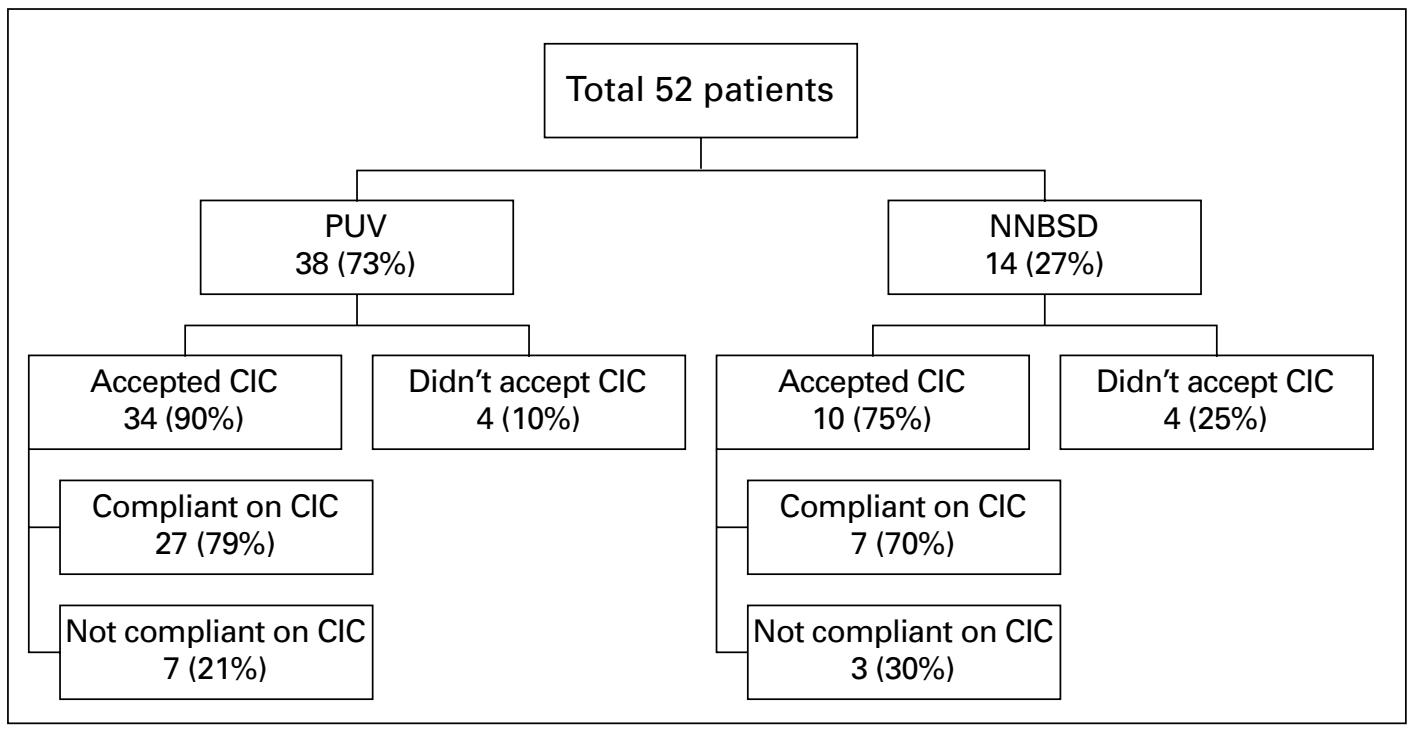

Fig. 1. Outcome with regard to compliance. $\mathrm{CIC}=$ clean intermittent catheterization. 


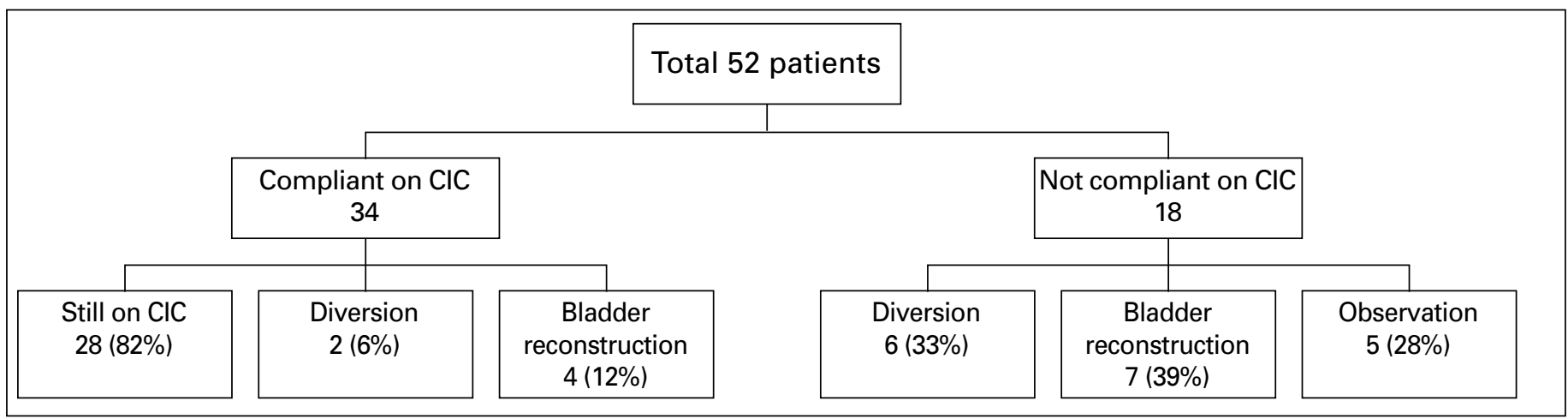

Fig. 2. Bladder fate after at least 2 years of follow-up. $\mathrm{CIC}=$ clean intermittent catheterization.

and their children; this should preferably take place before $\mathrm{CIC}$ starts. We found that this group discussion encourages compliance and alleviates a significant amount of fear in newly-treated families on the CIC program.

The only significant parameter observed for a successful program was the age at which $\mathrm{ClC}$ was initiated; age was significantly different $(p=0.03)$ for children beginning $\mathrm{CIC}$ per sensate urethra at or before the age of 4 , compared with those for whom $\mathrm{CIC}$ was started after the age of 4 . Other parameters, such as the presence of vesicoureteric reflux or hydronephrosis, had no significant effect on the success of the protocol.

Among the 52 patients, 34 (65\%) were still compliant with $\mathrm{CIC}$ after at least 2 years of follow-up (Fig. 1), and a total of 28 patients $(54 \%)$ are still on the CIC program with a stable bladder; none of these patients required incontinent diversion or bladder reconstruction (Fig. 2). Comparing both age groups, only $18 \%$ of those under the age of 4 needed surgical intervention, whereas $72 \%$ of the older children needed surgical intervention.

The group of patients described in this paper is difficult to manage. The described treatment modality is a challenge (because of the difficulty in convincing the children and their parents in the initial phase), however with proper compliance, it is worth trying. A positive outcome of the CIC method is the reduced need for surgical intervention later on.

As the current study is a retrospective study, the need for a larger prospective evaluation with a longer follow-up period with a control group is needed to further evaluate the final outcome of the CIC program per sensate urethra.

Table 1. Demographic data and age-related outcome for 52 patients.

\begin{tabular}{lcc}
\hline & PUV & NNBSD \\
\hline 44 males/8 females & 38 patients & 14 patients \\
\hline Age $\leq 4$ & $25(48 \%)$ & $80 \%$ compliant on CIC \\
\hline Age $>4$ & $27(52 \%)$ & $52 \%$ compliant on CIC \\
\hline $\begin{array}{l}\text { PUV }=\text { posterior urethral valve; NNBSD }=\text { non-neuropathic bladder sphincter dysfunction } \\
\text { (NNBSD); CIC }=\text { clean intermittent catheterization. }\end{array}$ & \\
\hline
\end{tabular}

\section{Conclusion}

The current study shows that $\mathrm{CIC}$ is a feasible option in the management of patients with sensate urethra who need to begin treatment as early as possible. Furthermore, patients who are compliant with $\mathrm{CIC}$ have a better chance of avoiding subsequent surgical intervention for the management of bladder non-compliance.

Department of Surgery, College of Medicine and King Khalid University Hospital, King Saud University, Riyadh, Saudi Arabia

Competing interests: None declared.

This paper has been peer-reviewed.

\section{References}

1. Teichman JM, Scherz HC, Kim KD, et al. An alternative approach to myelodysplasia management: aggressive observation and prompt intervention. J Urol 1994;152:807-11.

2. Mingin $\mathrm{GC}$, Baskin LS. Surgical management of the neurogenic bladder and bowel. Int Braz I Urol 2003:29:53-61.

3. Van Savage JG, Sackett CK, Wilhelm CL, et al. Indications for and outcomes of clean intermittent catheterization with normal genital sensation. J Urol 1997;157:1866-8.

4. Alpert SA, Cheng EY, Zebold KF, et al. Clean intermittent catheterization in genitally sensate children: patient experience with health related quality of life. J Urol 2005;174:1616-9.

5. Pohl HG, Baver SB, Borer JG, et al. The outcome of voiding dysfunction managed with clean intermittent catheterization in neurologically and anatomically normal children. BJU Int 2002;89:923-7.

6. Neel KF, Salem MA, Soliman SM, et al. Acceptance and compliance of clean intermittent catheterization among Saudi patients. Saudi Med J 2008:29:477-80.

Correspondence: Dr. Khalid Fouda Neel, Associate Professor and Consultant Pediatric Urologist, Division of Urology, Department of Surgery, King Khalid University Hospital, P0 7805, Riyadh 11472, Kingdom of Saudi Arabia; kfouda@ksu.edu.sa 